\title{
Alex Bierman'
}

\begin{abstract}
Previous research documents a robust relationship between financial strain and psychological distress in older adults, but does not clearly indicate whether financial strain changes with age in late life. We show that age is positively related to financial strain when age and cohort effects are separated using growth curve modeling, and this relationship is masked in conventional regression models by a negative effect of birth cohort. Age-related increases are stronger among women and elders with lower levels of education, but weaker when individuals were born substantially before or at the end of the Great Depression. This research demonstrates that many older adults are increasingly exposed to a pernicious socioeconomic stressor as they age, but these increases are circumscribed by placement in a matrix of historical and structural circumstances. Furthermore, analyses that do not distinguish between age and cohort effects may fail to detect these increases.
\end{abstract}

\section{Keywords}

aging, stress, education, gender, race

A primary mission in the sociology of mental health is the study of how psychological wellbeing is a consequence of individual placement in structures of inequality (Pearlin and Bierman 2013). Examination of financial strain is essential to this mission because financial strain reflects the lived experience of socioeconomic inequality through difficulty affording basic needs, such as food, clothing, and medical expenses (Pearlin 1999; Szanton, Thorpe, and Gitlin 2014). Financial strain is a particularly potent influence on mental health in older adults, with financial strain related to greater levels of a variety of aspects of psychological distress in late life, including depression, anxiety, and suicidal ideation (e.g., Almeida et al. 2012; Pudrovska et al. 2005). The relationship between financial strain and psychological distress in older adults is also quite robust, as it remains significant even when tested using analytic techniques that holistically control for all time-stable life course and selection factors as well as multiple contemporaneous health conditions (Bierman 2011).

The importance of financial strain for the mental health of older adults raises the question of whether and how financial strain may change over the course of late life. Research shows a surprising lack of clarity on the relationship between age and financial strain among older adults, with some research suggesting a negative relationship (e.g., Keith 1993; Krause 1993; Mirowsky and Ross 2010) but multiple additional studies

\footnotetext{
'University of Calgary, Calgary, AB, Canada

\section{Corresponding Author:}

Alex Bierman, Assistant Professor, Department of Sociology, University of Calgary, 2500 University Drive NW, Calgary, AB T2N IN4, Canada.

Email: aebierma@ucalgary.ca
} 
indicating a lack of a significant relationship (e.g., Goetting et al. 1996; Pudrovska et al. 2005; Szanton et al. 2008). To address these conflicting findings, this paper reconsiders how age may influence exposure to financial strain in late life by outlining a competing hypothesis framework. We describe theoretical arguments and empirical findings to support predictions of a positive or a negative association between age and financial strain in late life. We then describe how the consequences of age for financial strain may have been obscured in previous research due to a combination of birth cohort effects, selection effects, and differences in the relationship across core social statuses.

On the basis of these arguments, we analyze a longitudinal sample of older adults with analytic methods that take these three factors into account. The analyses show that a negative effect of birth cohort is likely to conceal a positive relationship between age and financial strain. Age effects are strongest among women and elders with low levels of education but are weakened in cohorts born at the end of or substantially prior to the Great Depression, resulting in some decreases in financial strain among men and elders with high levels of education born into cohorts with the weakest age effects. This research contributes to a sociological understanding of mental health by showing that many older adults are increasingly at risk for a pernicious socioeconomic stressor as they age, but such increases are differentiated based on a matrix of historical circumstances and status placement. A secondary contribution of this research is in showing that studies of the effects of age on stress exposure in late life are likely to be misleading unless age and cohort effects are properly distinguished.

\section{BACKGROUND}

We can hypothesize two patterns for the relationship between age and financial strain among older adults. First, we can hypothesize that financial strain decreases with age. Some have suggested that age brings greater "acquired efficiency," which in turn facilitates greater proficiency in managing money (Mirowsky and Ross 1999a). In addition, older adults tend to have decreased consumption habits with age (Danziger et al. 1982), and elders may also adjust their living standards downward (Stoller and Stoller 2003), both of which will allow individuals greater flexibility as they age to put economic resources toward the provision of basic necessities. Furthermore, tolerance of financial risk tends to decrease with age (Jianakoplos and Bernasek 2006), which will further guard against economic crises. In this case, then, we would expect a negative relationship between age and financial strain.

Conversely, we may also hypothesize that financial strain increases with age. Older age is associated with the cessation of work and the consequent diminishment of income (Plagnol 2011; Siminski and Yerokhin 2012), which is likely to leave individuals more at risk for financial problems (Gall and Evans 2000; Levecque et al. 2011). Beyond this, aging is associated with increasing health problems (Brown, O'Rand, and Adkins 2012; Yang and Lee 2009), which have been shown to sap financial reserves and increase risk of debt among older adults (Kim and Lee 2005; Kim, Yoon, and Zurlo 2012; J. Lee and Kim 2008). Furthermore, as levels of disability and infirmity tend to increase with age, older adults also tend to give up homes with paid mortgages and move into apartments and other rental dwellings that entail less maintenance but also require greater housing expenditures that can increase risk of financial strain (Cook and Settersen 1995). In this case, then, we would expect a positive relationship between age and financial strain.

At least some previous research supports both hypotheses. In support of a positive association between age and financial strain, research suggests that net worth decreases across late life, while the risk of poverty increases (Hardy 2009; Y. Lee 2004). A rising tension between financial resources and needs is likely to accompany these trends, thereby creating a general pattern of increasing financial strain with age. In addition, private insurance and state-sponsored payments in the form of Social Security are unlikely to consistently address risk of financial threats due to medical expenses (Crystal and Waehrer 1996; Short 2012; Stoller and Stoller 2003), thereby failing to obviate the increased risk of financial strain that is likely to accompany worsening health with age. Research on measures of financial strain presents more conflicting evidence, though. Some research suggests that financial strain may decrease with age in older adults (e.g., Keith 1993; Krause 1993; Mirowsky and Ross 2010), but multiple additional studies of older adults show a nonsignificant relationship between age and financial strain (e.g., Goetting 
et al. 1996; Pudrovska et al. 2005; Szanton et al. 2008). Despite arguments for a positive or negative relationship between age and financial strain, then, empirical research often indicates that neither relationship occurs. However, as we describe below, several factors may have combined to conceal a relationship between age and financial strain.

\section{Countervailing Effects of Birth Cohort}

Birth cohort refers to individuals born during the same time period, and "membership may be thought to index the unique historical period in which a group's common experiences are embedded" (Alwin et al. 2006:23). Birth cohort can have effects that are distinct from age because cohorts are shaped by the "conditions, barriers, and resources" into which they are born and experience throughout their lives (Keyes et al. 2010:1100). The distinction between age and birth cohort is important to take into account because a simple measure of age can index either "biographical time" in the life course or the historical period into which one was born (Alwin et al. 2006). The result is that conventional correlational analytic techniques used in previous research combine age and cohort effects (Lynch 2008), which can obscure both influences if they are in opposite directions.

We can hypothesize that birth cohort will be negatively or positively related to financial strain in older adults, thereby countering a positive or negative relationship between age and financial strain. A negative relationship between birth cohort and financial strain would mean that younger cohorts have greater exposure to financial strain than older cohorts in late life. In support of a negative relationship, some research suggests that older cohorts may have better money management skills (Mirowsky and Ross 1999b), which is likely instilled by more prolonged exposure to historical periods of economic adversity. In addition, patterns of consumption changed markedly over the twentieth century, with savings decreasing and consumer spending increasing and personal consumption increasing even during periods of economic stagnation (Gokhale, Kotliko, and Sablehaus 1996; Offer 2006; Smith 1987). The result is that younger cohorts in the United States are willing to take greater financial risks (Jianakoplos and Bernasek 2006), and more recent cohorts of older adults have more consumer and housing debt (Anguelov and Tamborini 2009) as well as lower levels of wealth (Wolff 2002). These findings suggest that younger cohorts may have less financial security in older adulthood and therefore greater exposure to financial strain.

A positive relationship between birth cohort and financial strain would mean that younger cohorts have lower financial strain than older cohorts in late life. In support of a positive relationship, older birth cohorts were more likely to enter adulthood experiencing restricted economic opportunities due to the Great Depression, and restricted opportunities early in the life course can reverberate over time with accumulating hardships and limited opportunities (Dannefer 2003; O'Rand 2002). These historical confines may have been especially pernicious for those from the earliest cohorts, as many of these individuals were more likely to experience adverse effects on life course trajectories due to the postponement or interruption of work and family life because of the demands of military service (Elder 1987; Elder, Shanahan, and Clipp 1994). Conversely, younger cohorts were more likely to establish careers in the postwar economic revitalization, which helped to create an early life course trajectory of financial success, as demonstrated by research showing that median household income in middle age increased substantially across these cohorts (Hughes and O'Rand 2004).

Differentiation in financial resources and human capital across cohorts may also lead to intercohort differences in the effects of age on financial strain. For example, if older cohorts are better prepared for late life due to better money management skills and greater frugality throughout the life course, a positive effect of age is likely to be weaker in older cohorts or a negative effect stronger. Contrariwise, if younger cohorts are better prepared for late life because they came of age during a time of economic expansion, we may observe that the positive effects of age are weaker or negative effects stronger in younger cohorts. Cohort differences in the effects of age could therefore further obscure age effects by combining contrasting effects across cohorts. In addition to examining whether countervailing age and cohort effects conceal the effects of age, then, it is also important to take cohort differentiation in age effects into account.

Although research on financial strain has not delineated age and cohort effects or examined 
cohort differences in the relationship between age and financial strain, analyses of a broader measure of deprivation in a British sample of adults shows that age and cohort can have opposing influences that lead to a nonsignificant effect of age when combined (Berthoud, Blekeaune, and Hancock 2009). Further, additional research shows that age and cohort effects can be confounded if they are not properly disentangled (e.g., Lynch 2003; Yang and Lee 2009). These findings underscore that birth cohort may have a countervailing influence on financial strain that is masking the relationship between age and financial strain.

\section{Selection Effects}

The experience of financial strain is likely to select individuals out of the population because financial strain is associated with mortality (Szanton et al. 2008). Consequently, even if individual strain increases with age, correlation analyses may show a negative or little relationship between age and financial strain because only the most financially robust remain at later ages (Dannefer 1987; Dupre 2007). A more appropriate test of the effects of age would therefore consider individual age-based trajectories of financial strain over time and also take into account differences in financial strain between those who exit the study and those who complete it. It is especially important to examine whether these age-based trajectories differ due to selection (Yang and Land 2013). The increase in risk of mortality that is likely to follow increases in financial strain implies that age will have a positive relationship among individuals who exit the study, while those who remain in the study may experience little increase in strain with age or even a decrease. Combining these trajectories may lead researchers to overlook a group-specific positive relationship between age and financial strain.

\section{Differences across Core Social Statuses}

Stress exposure tends to be differentiated based on social statuses that are fundamental to social stratification, such as education, race, and gender (Pearlin and Bierman 2013). Hypotheses regarding positive and negative effects of age may therefore both be correct but specific to different locations in structures of power, privilege, and prestige.
Ignoring these social status variations would lead to a combination of contrasting relationships, in turn potentially obscuring a group-specific effect or creating the appearance of little association altogether.

Education, race, and gender are likely to differentiate the relationship between age and financial strain in late life because each stratifies the accumulation of financial resources and expenditures throughout the life course. Education unlocks subsequent status attainment by facilitating access to higher-status jobs and earnings that can lead to greater financial reserves in late life as well as jobs with benefits, such as pensions, that can have lifelong consequences for economic wellbeing (Elman and O'Rand 2004; Hardy 2009; Treiman 1992). Conversely, research taking mortality into account indicates that health problems are more likely to arise with age for individuals with low levels of education (Dupre 2007), which can in turn sap financial reserves. Similarly, African American elders grew to maturity and lived much of their adult lives during a time of substantial institutionalized racism, which will restrict status attainment throughout the life course, thereby leading to lower levels of financial reserves in later life (Shea, Miles, and Hayward 1996). Moreover, African American elders are likely to continue to reside in racially segregated neighborhoods that have less access to medical facilitiesthereby requiring greater cost of transportationas well as restricted availability of consumer outlets that will increase the cost of living (Kwate 2008; Morland et al. 2002; Williams and Collins 2001; Williams and Sternthal 2010). Gender is also important to take into account because older women lived much of their adulthood with gendered occupational stratification and fewer economic opportunities than men, resulting in lower levels of wealth in later life that can increase risk of exposure to financial strain (Albelda 1986; Denton and Boos 2007; Warren, Hauser, and Sheridan 2002). Moreover, women tend to live longer than men (Barford et al. 2006), and because of this, women are likely to more stringently apportion savings and exhaust financial reserves across the extent of late life. Altogether, we may be more likely to observe a negative or nonsignificant relationship between age and financial strain among older adults with more advantaged social statuses and a positive relationship among less advantaged elders. 


\section{Summary of Aims}

In summary, this research seeks to reconsider the relationship between age and financial strain in older adults. Although previous research inconsistently documents a relationship between age and financial strain, theory and evidence support competing hypotheses that age will be positively or negatively associated with financial strain. We argue that birth cohort effects, selection effects, and differences across core social statuses are each likely to contribute to obscuring the agestrain relationship. Within this research, we examine the relationship between age and financial strain while taking each of these factors into account.

\section{METHOD}

\section{Data}

Data for this research come from the Aging, Stress and Health (ASH) study, which is a longitudinal study of people ages 65 years and older residing in the District of Columbia and two adjoining Maryland counties, Prince George's and Montgomery. Consistent with the purpose of the project to investigate status inequality and health disparities, a socially and economically diverse sample was sought. The three locales subsume this diversity. Sample selection and recruitment began with Medicare beneficiary files for the three areas. In addition to the names of all people 65 years and older who are entitled to Medicare, the files provided information about the race and gender of each beneficiary. To maximize the social and economic diversity within the sample, a total of 4,800 names were randomly selected - equally divided among the three locales, African Americans and whites, and women and men-creating 12 groups, each containing 400 names. However, the goal was to enlist a sample of 1,200 people living independently (with approximately 100 people in each of the 12 groups). Out of the 4,800 , a subset met the study criteria, and approximately 65 percent of all eligible respondents who were contacted agreed to participate, yielding 1,167 cases. The age distribution within the four gender-race groups was similar to the population from the 2000 Census (Schieman and Plickert 2007).

Interviews for wave 1 occurred during 20012002. Wave 2 was a year later and comprised 1,000 respondents (an 85.7 percent retention rate), wave 3 was two years after wave 1 and comprised 925 of the original respondents (a 79.3 percent retention rate), wave 4 was four years after the first wave and comprised 789 respondents (a 67.6 percent retention rate), and wave 5 was five years after the first wave and comprised 716 respondents (a 61.4 percent retention rate). Although this is a fairly strong retention rate given the age of the sample, analytic techniques described below address sample attrition. Purposeful exclusion of cases for which there was insufficient cohort size resulted in an $N$ of 1,121 . Subsequent loss of cases due to nonresponse on timestable measures was quite slight, totaling 20 cases. The result was a sample size of 1,101 , which produced 4,344 person-year observations of financial strain.

\section{Measures}

Financial Strain. The measure of financial strain was adapted from a seminal paper by Pearlin et al. (1981) and asked respondents to indicate difficulty paying for five essential needs: housing, food, transportation costs, medical expenses, and clothing. Responses were on a scale of 1 (not at all difficult) to 3 (very difficult). A principal components analysis of these items at each wave indicated only one component with an eigenvalue above 1 , with all loadings above 0.70 , and the scale also indicated sufficient reliability across waves (Cronbach's alpha .82-.87). Responses at each wave were summed to indicate financial strain.

Cohort. Derivation of cohorts is based on specific historical events that demarcate structural changes in barriers and resources (Keyes et al. 2010). These events are the beginning and end of World War I (WWI) from 1914 to 1918, the post-WWI period that included a recession before the economic boom of the Roaring Twenties in 1922, the stock market crash of 1929 that signaled the start of the Great Depression, and some economic rebound that began in 1934 through 1936 (although it should be noted that even with this rebound, conditions were still dire, as real GDP remained below 1929 levels until 1936, and even in 1936, real GDP was only at a level similar to 1929). Further, because individuals could experience a substantially different set of conditions depending on the extent of their exposure to these 
historical circumstances, it is more accurate to divide longer historical periods into "early" and "late" cohorts. On the basis of this framework, we created a six-level measure of birth cohort: WWI (1914-1918), post-WWI (1919-1921), early Roaring Twenties (1922-1925), late Roaring Twenties (1926-1929), early Great Depression (1930-1933), and late Great Depression (19341936). These intervals are approximately evenly spaced, lending support to using this measure as an interval predictor. Additional nominalization tests indicated no significant improvement in model fit by using this measure as a set of dichotomous predictors (McClendon 2002), which is particularly strong evidence for using this measure as an interval predictor because the nominalization test is highly sensitive in even moderately large samples (Fox 2008). Cohort is median centered in all models at the 1926-1929 cohort to increase interpretability.

Age. The measure of age is based on total number of days since birth, calculated using the user-written Stata add-on "personage," with days divided by 365 to produce a measure of age in years. ${ }^{1}$ Methodological sources recommend centering level 1 predictors based on the mean for a higher-order unit to disentangle the consequences of higher-order and lowerorder influences (e.g., Enders 2013; Hoffman and Stawski 2009). We therefore centered the age variable based on the mean age for the respective cohort to which a respondent belonged, with this information provided in Table 1.

Core Social Statuses. The core social statuses addressed in this research are education, race, and gender. Education was measured on a scale of 1 (eighth grade or less) to 6 (college degree or more). Previous research has used this measure as a linear predictor (e.g., Milkie et al. 2008), and ancillary analyses confirmed its suitability as a linear predictor in this research, showing little substantial increase in predictive power with one or a set of dichotomous predictors, even when comparing different points of categorization. Education is centered in all analyses at high school degree. Race is a dichotomous variable in which $1=$ African American. Gender is a dichotomous variable in which $1=$ women.

Attrition. A dichotomous variable indicating inclusion in the final wave of the survey $(1=$ 
Table 2. Mean of Social Status and Control Variables at Baseline.

\begin{tabular}{ll}
\hline Variable & Mean \\
\hline Education & 4.444 \\
Race (I = black) & 0.500 \\
Gender (I = women) & 0.493 \\
Attrition & 0.370 \\
Montgomery County & 0.350 \\
Prince George's County & 0.329 \\
Not raised with both parents & 0.32 I \\
Non-native & 0.058 \\
Number of siblings & 3.595 \\
Married & 0.540 \\
\hline
\end{tabular}

Note. $N=I, I 0 I$. The standard deviation for education is 1.692 and for number of siblings is 2.8 .

not present) was used to measure attrition, although substantively similar results were obtained when a measure of number of waves of participation was used in alternative analyses.

Control Measures. We include multiple measures of family background because holding these factors constant shifts attention from proximal resources of origin to broader transitions in the historical context associated with birth cohort. These measures include number of siblings, nativity (a dichotomous variable in which $1=$ not born in the United States), and also whether an individual was with both birth parents while growing up $(1=$ no $){ }^{2}$ Individual variation in financial resources due to marital status was taken into account with a time-varying dichotomous control (in which $1=$ married), which was centered within person. Analyses are adjusted for sampling based on county of residence at baseline with a set of dichotomous indicators that contrasted Prince George's and Montgomery Counties with Washington, D.C. Table 2 lists descriptives at baseline for the social status and control measures.

\section{Methods of Analysis}

We begin by examining the relationship between age and financial strain in an ordinary least squares (OLS) regression with standard errors adjusted to account for repeated observations of individuals over time (Snijders and Bosker 2012); in keeping with conventional application of regression techniques, age is not centered in these analyses. We then employ multilevel modeling to create growth curve models that separate age and cohort effects. This strategy uses respondent age as the measure of time, thereby depicting age-based trajectories of financial strain (Miyazaki and Raudenbush 2000). Adapting this strategy and its description from Yang and Land (2013), the basic model is as follows:

$$
\begin{gathered}
Y_{t i}=\beta_{0 i}+\beta_{1 i} \text { Age }_{t i}+e_{t i} \\
\beta_{0 i}=\gamma_{00}+\gamma_{01} \text { Cohort }_{i}+\sum_{q} \gamma_{0 q} Z_{q i}+w_{0 i}
\end{gathered}
$$

$$
\beta_{1 i}=\gamma_{20}+w_{1 i}
$$

Equation 1 is the level 1 repeated observation model, in which $Y_{t i}$ is the financial strain response variable for respondent $i$ at time $t$, for $i=1 \ldots, n$ and $t=1, \ldots, T_{i}$; $T_{i}$ is the number of measurements and ranges from 1 to 5 . Within Equation $1, e_{t i}$ is the random within-person error for person $i$ at time $t$. Because Age $_{t i}$ is the age of respondent $i$ at time $t$, the associated coefficient, $\beta_{1 i}$, indicates the expected rate of increase or growth rate per year of age for person $i$.

The coefficient $\beta_{0 i}$ is the intercept, which can be interpreted as the expected financial strain response score for person $i$ at the mean age for a respective cohort. Equation 2 shows that this intercept varies by person-level (i.e., time-stable) characteristics, such as birth cohort, with $\gamma_{01}$ indicating the mean difference in financial strain between cohorts; $\gamma_{0 q}$ is the coefficient for person-level covariates, such as education, race, and gender. Further, $w_{0 i}$ indicates residual random variation in the intercept across respondents. Equation 3 models the slope for age, $\beta_{1 i}$, and $\gamma_{00}$ indicates the expected linear rate of change per year of age, while $w_{1 i}$ indicates that this rate of change is expected to vary across individuals. Equation 3 can be extended to include personlevel predictors of $\beta_{1 i}$, referred to as "cross-level interactions," thereby showing whether variation in the relationship between age and financial strain is due to person-level characteristics (Snijders and Bosker 2012).

One issue in growth curve modeling is that of attrition over time, but the multilevel model 
incorporates all individuals in estimation of trajectories, regardless of the number of waves in which the respondent participated (Yang and Land 2013). Loss of observations due to mortality or other reasons for attrition is therefore much less of a threat to model estimates than in models that typically use listwise deletion. The multilevel model's treatment of data lost due to attrition does depend on the assumption that missing data are "missing at random," in which missingness can be predicted by the model covariates (Snijders and Bosker 2012). However, the use of a number of core social status predictors helps to ensure that the primary causes of attrition are likely either directly taken into account or indirectly taken into account because these social statuses are fundamental "upstream" causes of later health conditions that may lead to attrition (Phelan, Link, and Tehranifar 2010). Further, Yang and Land (2013) suggest adding a measure of attrition as a person-level covariate to correct parameter estimates for biases due to attrition, and we examine the consequences for model estimates of including such a measure. Analyses are conducted using Stata 13.1 using standard errors that are robust to heteroskedasticity (Hayes and Cai 2007).

\section{RESULTS}

Model 1 of Table 3 presents an OLS regression in which financial strain is predicted by age and the controls. This model shows that age is not significantly related to financial strain. This model serves as a useful comparison to the growth curve analyses by showing that the application of conventional analytic methods to the current data provides results in common with several previous studies: There is little evidence of a relationship between age and financial strain. Thus, dissimilarities between the results of the growth curve analyses and previous research are likely not due to variations in the age-strain relationship across data sources. Furthermore, additional analyses showed that a squared term for age was not significant in a conventional regression model, nor were interactions between the focal social statuses and either the linear or squared term for age.

Model 2 in Table 3 presents the first growth curve model, in which age is used as a timevarying predictor of financial strain. Here, we see that age is positively and significantly related to financial strain, indicating that financial strain increases with age. Model 3 shows that a squared term for age is not significant, indicating that the overall trend in the data is for a positive linear relationship between age and financial strain. It should be stressed that age and cohort effects were separated in the growth curve models through the use of centering, suggesting that the difference in the strain-age associations between regression and growth curve models is because the regression model confounds age and cohort effects. Model 4 addresses this possibility by adding cohort and as a predictor to the growth curve model, showing that the relationship between cohort and financial strain is significant and negative. Further, model 5 shows that a squared term for cohort is not significant, in turn supporting a linear negative relationship between birth cohort and financial strain. The OLS regression therefore does not demonstrate a significant effect of age because this model combines the positive effect of age with a negative effect of cohort. When these opposing influences are disentangled in the growth curve model, we see that age is positively associated with financial strain. This interpretation was reinforced in an ancillary growth curve model in which age was grand-mean centered, a strategy that confounds age and cohort effects (Hoffman and Stawski 2009). In this model, age was not a significant predictor, showing that it is only by separating age and cohort effects that the positive effect of age becomes clear.

The way that age and cohort combine to cancel each other out is depicted in Figure 1, which shows model-based predicted means across eight years of aging; eight years was chosen so as to maintain a consistent interval of aging across cohort. Here, we see that individual levels of financial strain do increase with age, but these increases are placed progressively lower across older cohorts due to the negative effect of cohort. The result is that, if we compare simple means across ages, we see little difference. For example, the predicted means for a 66-year-old from the youngest cohort and an 88-year-old from the oldest cohort are nearly the same. Correlational analyses that compare means across ages are therefore unlikely to detect the positive relationship between age and financial strain because these methods combine countervailing age and cohort effects.

Although the analyses showed an overall positive linear relationship between age and financial strain, the significant variance in the random 


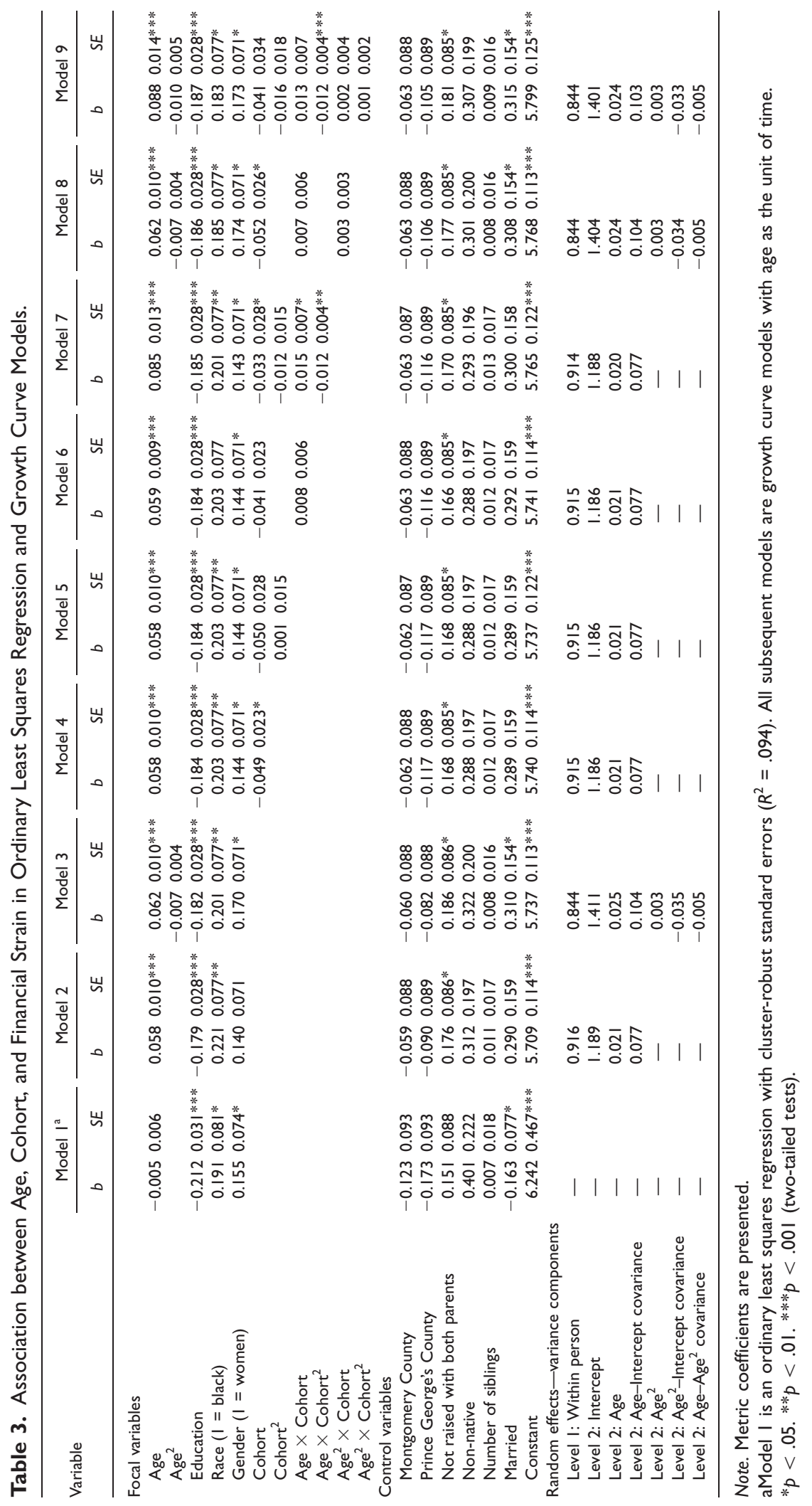




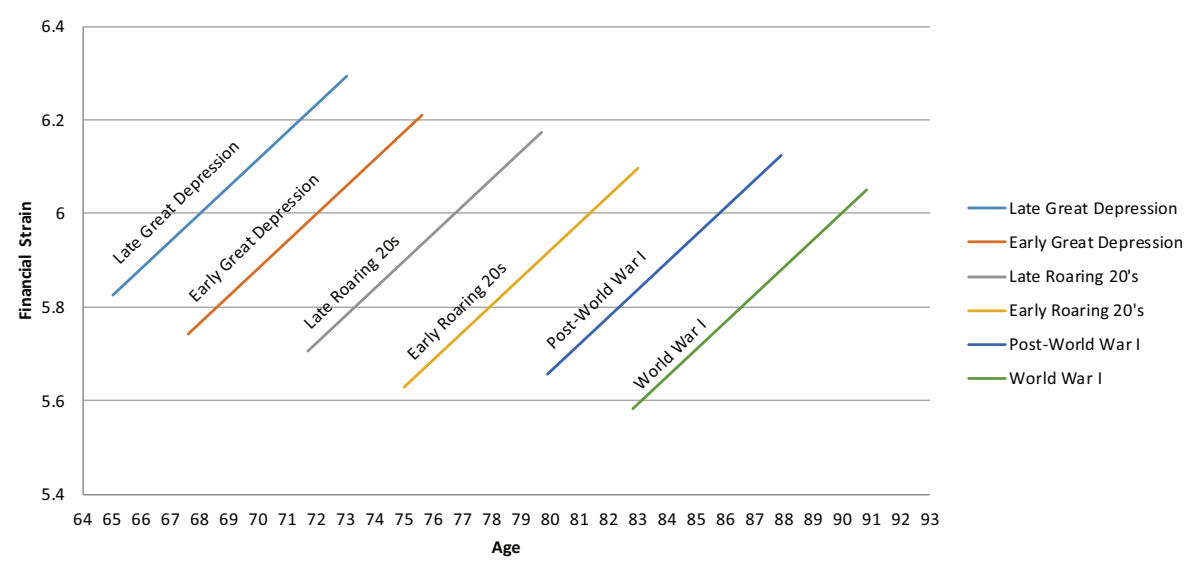

Figure I. Trajectories of Financial Strain by Cohort.

effects for both the linear and quadratic terms for age indicated significant interindividual variation from this relationship. The question of whether cohort contributes to these interindividual differences is addressed in the next set of models. Model 6 tests an interaction between age and cohort, and this interaction is not significant. This would seem to suggest that cohort does not moderate the effects of age, but model 7 shows that an interaction between a squared term for cohort and age is significant. Model 8 shows that an interaction between the squared term for age and the linear term for cohort is not significant, while model 9 shows that the interaction between the squared term for cohort and the squared term for age is not significant. Overall, these analyses show that cohort membership contributes to variations in the linear increase in financial strain with age but not deviations from linearity; furthermore, because a squared term for cohort interacts with the linear term, the extent to which birth cohort modifies the linear increase in financial strain changes across cohort.

Figure 2 helps explain the meaning of this nonlinear interaction by graphing model-predicted changes in financial strain across eight years of aging separately by cohort. This figure shows little increases in financial strain in the earliest and latest cohorts but substantial increases in financial strain among the middle cohorts. The potential reasons for these variations will be addressed in the Discussion section, but these analyses help explain how some studies have found a negative relationship between age and financial strain.
Because both the earlier and more recent cohorts indicate little increase in financial strain with age, in samples with a preponderance of elders born substantially before or toward the end of the Great Depression, cohort effects are likely to be predominant. Accentuated cohort effects will in turn increase the likelihood that methods that do not separate age and cohort effects show a negative relationship between age and financial strain.

Table 4 addresses whether selective attrition influenced results, while retaining the interactions between age and cohort to take cohort variations in age effects into account. Model 1 shows that the indicator of attrition is not significant, indicating that individuals included in the final wave of the study were not significantly lower in financial strain than those who exited early. Model 2 interacts age with attrition, while model 3 tests an interaction between attrition and a squared term for age, and neither interaction is significant. ${ }^{3}$ These analyses therefore show that remaining in the sample is not associated with financial strain and also that the relationship between age and financial strain did not differ by attrition. As both the main and moderating effects of attrition were nonsignificant, these predictors are dropped from subsequent analyses.

Table 5 examines whether the relationship between age and financial strain differs across core social statuses. Model 1 shows that both education and gender interact with age. Figures 3 and 4 depict the meaning of these interactions, with Figure 3 showing age-related changes in financial 


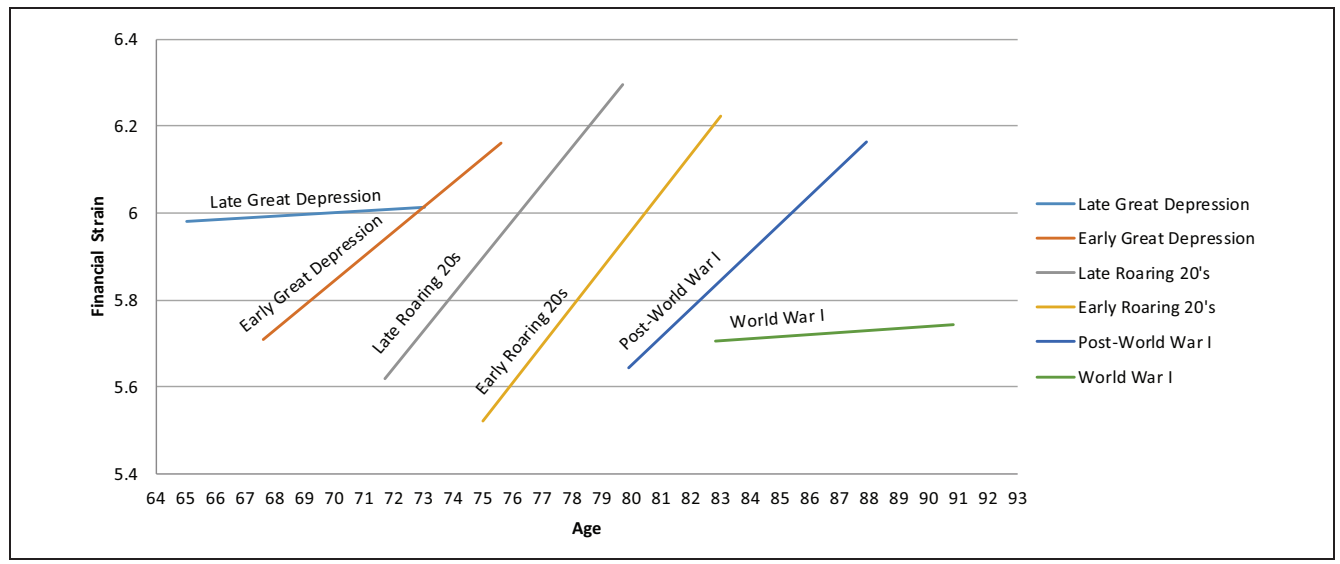

Figure 2. Differences in Trajectories of Financial Strain Across Cohorts.

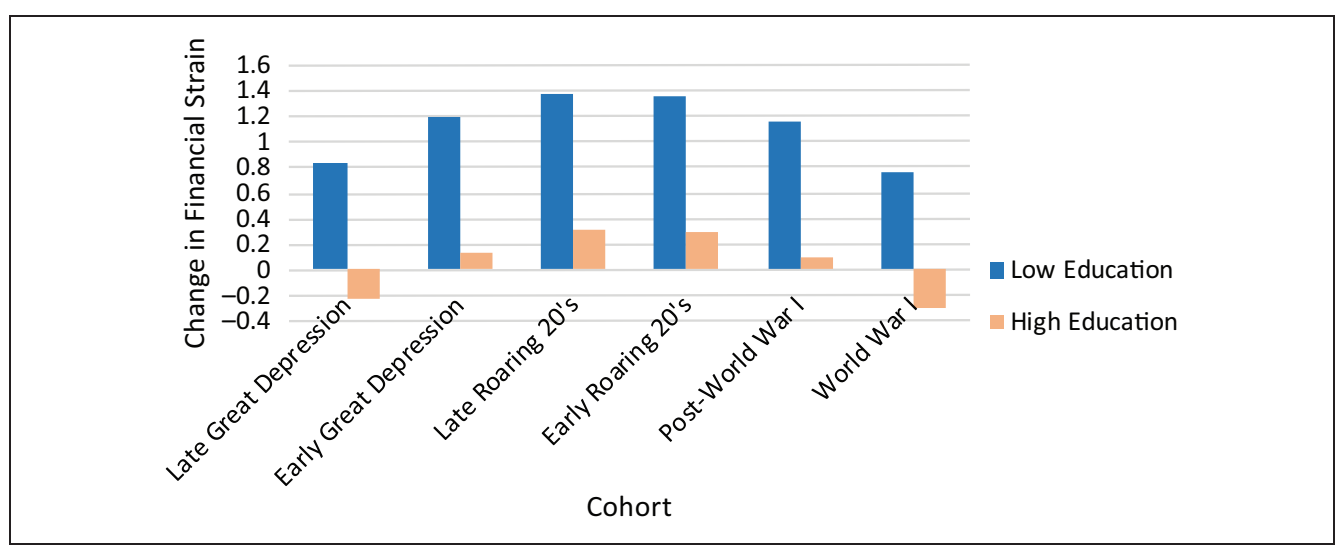

Figure 3. Changes in Financial Strain by Education and Cohort.

strain separately for low (less than a high school degree) and high (college degree) levels of education, and Figure 4 showing these changes separately for men and women. Both figures show a similar pattern, as elders in less advantaged statuses experience an increase in financial strain across cohorts, although these increases are stronger in cohorts showing stronger overall increases in financial strain. Advantaged statuses diminish these increases, though, with the result that in the cohorts with the weakest age effects, we actually see some decreases in financial strain with age. These analyses therefore suggest that arguments for increases and decreases in financial strain are both correct but are circumscribed by a combination of social status and cohort variations.
Model 2 examines whether the relationship between age and financial strain deviates from linearity across core social statuses by interacting a squared term for age with the measures of social statuses. Interactions involving education and gender are not significant, indicating that the education and gender differences identified in the previous model are not modified further due to deviations from linearity, but race interacts with the squared term for age. Figure 5 illustrates the meaning of this interaction by showing that black elders experience a substantially stronger increase in financial strain than white elders, but black elders also experience substantial reversal in these increases. White elders experience less rapid but more linear increases in financial strain over time. These analyses therefore suggest that black 


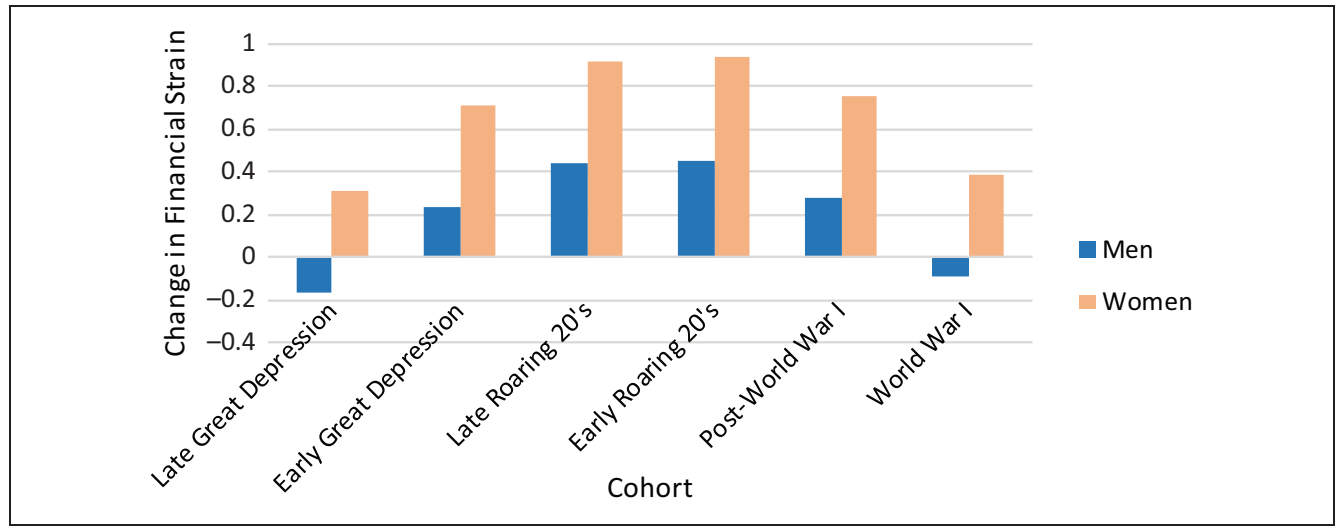

Figure 4. Changes in Financial Strain by Gender and Cohort.

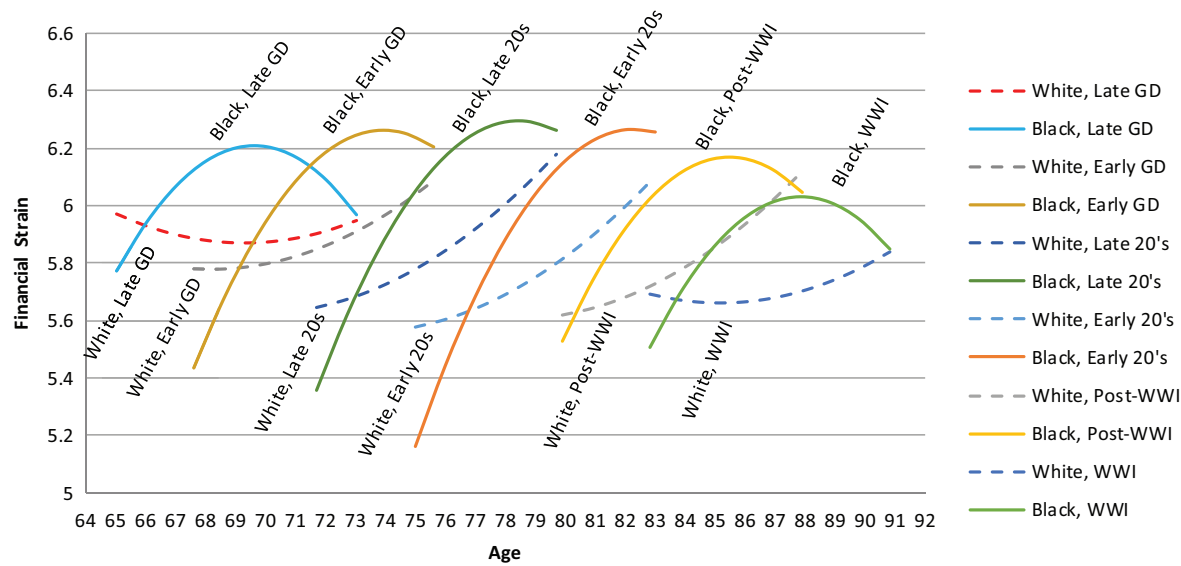

Figure 5. Race-Specific Trajectories of Financial Strain by Cohort.

elders were at greater risk for increases in financial strain associated with aging but were also able to utilize greater "acquired efficiency" in response to financial transitions associated with aging, with the result that only in cohorts with stronger increases in financial strain did black elders ultimately experience substantially greater financial strain than whites.

\section{DISCUSSION}

This research began with competing hypotheses for a positive and negative relationship between age and financial strain, but our analyses showed that age is positively related to financial strain when age and cohort effects are separated, with a negative effect of birth cohort obscuring the positive effect of age in a conventional regression model. The specific mechanisms for the negative effects of birth cohort are beyond the scope of this research, but more recent cohorts of older adults are entering late life with greater debt and lower levels of wealth (Anguelov and Tamborini 2009; Wolff 2002), and it is possible that an increasing cultural emphasis on consumption has led to reduced financial stability in late life. Additional research should more closely examine why risk of financial strain appears to strengthen in younger cohorts, as well as how this pattern may be reversed.

More generally, this paper joins a small but growing body of research demonstrating that age effects are liable to be confounded with cohort 
Table 4. Differences in Financial Strain and the Age-Strain Relationship by Sample Attrition.

\begin{tabular}{|c|c|c|c|c|c|c|}
\hline \multirow{2}{*}{ Variable } & \multicolumn{2}{|c|}{ Model I ${ }^{\mathrm{a}}$} & \multicolumn{2}{|c|}{ Model 2} & \multicolumn{2}{|c|}{ Model 3} \\
\hline & $b$ & SE & $b$ & SE & $b$ & SE \\
\hline \multicolumn{7}{|l|}{ Focal variables } \\
\hline Age & 0.085 & $0.013^{* * *}$ & 0.086 & $0.013^{* * *}$ & 0.091 & $0.014 * * *$ \\
\hline $\mathrm{Age}^{2}$ & & & & & -0.011 & $0.004 *$ \\
\hline Cohort & -0.037 & 0.029 & -0.037 & 0.029 & -0.033 & 0.028 \\
\hline Cohort $^{2}$ & -0.013 & 0.015 & -0.013 & 0.015 & -0.010 & 0.015 \\
\hline Age $\times$ Cohort & 0.015 & $0.007 *$ & 0.015 & $0.007 *$ & 0.015 & 0.007 \\
\hline Age $\times$ Cohort $^{2}$ & -0.012 & $0.004 * *$ & -0.012 & $0.004 * *$ & -0.011 & $0.004 * *$ \\
\hline Attrition & 0.061 & 0.083 & 0.055 & 0.094 & -0.030 & 0.100 \\
\hline Age $\times$ Attrition & & & -0.004 & 0.035 & 0.001 & 0.038 \\
\hline Age $^{2} \times$ Attrition & & & & & 0.021 & 0.012 \\
\hline Constant & 5.744 & $0.127 * * *$ & 5.744 & $0.127 * * *$ & 5.783 & $0.125 * * *$ \\
\hline \multicolumn{7}{|l|}{ Random effects-variance components } \\
\hline Level I: Within person & 0.914 & & 0.915 & & 0.845 & \\
\hline Level 2: Intercept & 1.188 & & 1.187 & & 1.401 & \\
\hline Level 2: Age slope & 0.020 & & 0.020 & & 0.023 & \\
\hline Level 2: Age-Intercept covariance & 0.077 & & 0.077 & & 0.103 & \\
\hline Level 2: $\mathrm{Age}^{2}$ & - & & - & & 0.003 & \\
\hline Level 2: $\mathrm{Age}^{2}-$ Intercept covariance & - & & - & & -0.033 & \\
\hline Level 2: Age-Age covariance & - & & - & & -0.005 & \\
\hline
\end{tabular}

Note. Metric coefficients are presented. All models include control variables presented in Table 3.

${ }^{*} p<.05$. ${ }^{* *} p<.0$ I. ${ }^{* * *} p<.001$ (two-tailed tests).

effects if the two are not properly specified (e.g., Berthoud et al. 2009; Lynch 2003; Yang and Lee 2009). It remains quite common for researchers studying aging and the stress process to use methods that do not separate age and cohort, though, and the sum total of findings across studies suggests that both researchers and reviewers should look skeptically upon research that purports to examine "age effects" using conventional regression models. Even if researchers employing regression analyses explicitly state that observed effects may be due to age or cohort, this is likely not sufficient because contrasting age and cohort effects can easily lead to a set of findings that obscures critical dimensions of the stress process.

Increases with age were weaker in cohorts born at the tail end or substantially prior to the Great Depression, thereby supporting dual arguments for the weakening of age effects in the oldest and youngest cohorts. Those born at the end of the Great Depression came of age during an era of rapid economic expansion that likely helped to provide this cohort with better opportunities to prepare for increases in risk of financial strain that may occur with age. Conversely, members of the WWI cohort combined the benefits of a substantial amount of maturation during a time of economic expansion with exposure to economic tribulations during the transition to adulthood that likely instilled a lifetime of financial frugality. These findings suggest that older studies with a larger component of the WWI cohort were especially likely to find a negative age-strain relationship because negative cohort effects were emphasized due to weaker age effects in this cohort.

Social status differences are also important to take into account, as financial strain tended to increase precipitously in late life across birth cohorts in women and elders with lower levels of education. These findings show how core stratifying factors continue to have substantial consequences for mental health well into late life. For individuals who experienced greater structural barriers to economic achievement, late life is a time of increasing exposure to a potent stressor, such as financial strain. The risk of stress exposure may be blunted somewhat by membership in a more advantaged birth cohort, though, as these increases were weaker in cohorts with less substantial age effects. 
Table 5. Differences in the Age-Strain Relationship by Core Social Statuses.

\begin{tabular}{|c|c|c|c|c|}
\hline \multirow{2}{*}{ Variable } & \multicolumn{2}{|c|}{ Model I } & \multicolumn{2}{|c|}{ Model 2} \\
\hline & $b$ & SE & $b$ & SE \\
\hline \multicolumn{5}{|l|}{ Focal variables } \\
\hline Age & 0.121 & $0.025 * * *$ & 0.117 & $0.025 * * *$ \\
\hline $\mathrm{Age}^{2}$ & & & 0.000 & 0.009 \\
\hline Education & -0.223 & $0.030 * * *$ & -0.229 & $0.034 * * *$ \\
\hline Race $(\mathrm{I}=$ black $)$ & 0.177 & $0.080 *$ & 0.289 & $0.085 * *$ \\
\hline Gender ( $I$ = women $)$ & 0.180 & $0.074 *$ & 0.162 & 0.085 \\
\hline Cohort & -0.036 & 0.028 & -0.033 & 0.028 \\
\hline Cohort $^{2}$ & -0.014 & 0.015 & -0.011 & 0.015 \\
\hline Age $\times$ Cohort & 0.012 & 0.007 & 0.012 & 0.007 \\
\hline Age $\times$ Cohort $^{2}$ & -0.012 & $0.004 * * *$ & -0.011 & $0.004 * *$ \\
\hline Age $\times$ Education & -0.032 & $0.007 * * *$ & -0.033 & $0.008 * * *$ \\
\hline Age $\times$ Race & -0.015 & 0.019 & -0.006 & 0.020 \\
\hline Age $\times$ Gender & 0.044 & $0.019 *$ & 0.044 & $0.019 *$ \\
\hline $\mathrm{Age}^{2} \times$ Education & & & 0.002 & 0.003 \\
\hline $\mathrm{Age}^{2} \times$ Race & & & -0.025 & $0.008 * *$ \\
\hline $\mathrm{Age}^{2} \times$ Gender & & & 0.007 & 0.008 \\
\hline Constant & 5.826 & $0.126 * * *$ & 5.805 & $0.136 * * *$ \\
\hline \multicolumn{5}{|l|}{ Random effects - variance components } \\
\hline Level I: Within person & 0.913 & & 0.839 & \\
\hline Level 2: Intercept & 1.188 & & 1.392 & \\
\hline Level 2: Age slope & 0.016 & & 0.020 & \\
\hline Level 2: Age-Intercept covariance & 0.072 & & 0.098 & \\
\hline Level 2: $\mathrm{Age}^{2}$ & - & & 0.003 & \\
\hline Level 2: Age ${ }^{2}$-Intercept covariance & - & & -0.314 & \\
\hline Level 2: Age-Age ${ }^{2}$ covariance & - & & -0.005 & \\
\hline
\end{tabular}

Note. Metric coefficients are presented. All models include control variables presented in Table 3. $* p<.05 . * * p<.01 . * * * p<.001$ (two-tailed tests).

Cohort differentiation in the effects of age combined with advantages among men and elders with high levels of education to create enervated growth in cohorts with strong age effects and small decreases in cohorts with the weakest age effects. These results suggest that arguments that decreased consumption habits and greater "acquired efficiency" will lessen financial strain as individuals age are correct (Mirowsky and Ross 1999a), but are circumscribed by placement in a matrix of historical and structural circumstances. Individuals who both were born into a time that promoted economic stability in late life and occupied social statuses that facilitated access to structural resources that bolstered preparation for late life were likely able to mobilize accrued experience and transitions associated with aging to diminish exposure to financial strain. Thus, although arguments for decreases in financial strain may be correct, this research also suggests that such decreases are most likely to occur under a relatively fortuitous combination of historical and structural advantages.

Explanations for acquired efficiency are given further support in the findings for race differences in the effects of aging. Black elders experienced more rapid increases in financial strain than white elders but were also able to consequently diminish these gains. This pattern of results suggests that the greater structural discrimination that blacks experience throughout the life course created greater risk of exposure to financial strain with age, but also these structural barriers created greater human capital or community resources within black communities that helped black elders reverse gains in financial strain. Additional research should therefore examine the resources that help black elders weaken or reverse increases 
in financial strain to help facilitate understanding of the way that structurally disadvantaged elders can prevent age-based increases in financial strain.

Findings in regard to social status differences in the effects of age likely further help to explain why some research has failed to detect a relationship between age and financial strain. Combining stronger effects among women and the less educated with weaker effects among men and the highly educated presents a weaker depiction of this relationship than is experienced by many older adults. Social status differences could also help explain how some previous research has found negative effects of age. For example, Mirowsky and Ross (2010) report the results of a latent growth curve model suggesting negative cohort effects that are similar to those observed here but also negative age effects. They do not examine social status differences in these age effects, though, and the current research suggests that while compositional differences may lead to interstudy differences in findings for the main effects of age, analyses of status-specific trajectories would likely reveal greater similarities between data sets. The results of the current research therefore suggest that future research should routinely consider social status differences when examining the relationship between age and financial strain because this relationship is likely to vary substantially across core social statuses. Importantly, the results of the current analyses also showed that status differences in the effects of age were evident in the growth curve models, but not regression analyses, because birth cohort did not significantly interact with the social statuses. By combining age and cohort effects, then, conventional regression analyses may also overlook important status contingencies in the way that aging influences stress exposure.

We found no evidence that selection was related to mean levels of financial strain or influenced the relationship between age and financial strain, but one weakness with this component of the analyses is that we did not have access to specific indications of mortality. This is especially important in light of additional analyses showing an unstable interaction between attrition and the nonlinear term for age. It is possible that we might have found a more consistent effect of selection if we had been able to differentiate selection due to morality from other reasons for attrition. Additional research should therefore examine whether it is selection specifically due to mortality that influences estimates of the relationship between age and financial strain in late life, especially whether the age-strain relationship is stronger in those experiencing mortality.

In closing, the current analyses suggest that late life is a time of increasing exposure to a stressor that can have potent deleterious consequences for mental health, but increases in financial strain are circumscribed by historical and social conditions, with those born into adverse economic historical circumstances and occupying disadvantaged social statuses most likely to bear the brunt of increasing financial stress in late life. This pattern of findings is important because it illustrates how a matrix of historical and social circumstances is able to structure individual psychological well-being well into late life. Such patterns are clear, though, only when methods of analysis are employed that properly delineate age and cohort effects. Research that fails to do so risks underestimating exposure to pernicious stressors, especially in the most vulnerable populations.

\section{ACKNOWLEDGMENT}

National Institute on Aging Grant Award AG17461 (Leonard I. Pearlin, principal investigator) supported this work.

\section{NOTES}

1. Because the date of interview was not available for the fifth wave, age at wave 5 was created by adding in number of days since previous interview based on whole years (i.e., 365 for a year). Sensitivity analyses based on earlier waves indicated little bias due to this approach.

2. We do not control for contemporaneous, income, wealth, employment status, or health conditions because these are likely to be explanatory mechanisms for the effects age on financial strain, and utilizing mechanisms of age as background controls would errantly ascribe associations with age as spurious (Aneshensel 2013). Similarly, we do not control for life histories of income or occupational incumbency because such factors are likely to be explanatory mechanisms for cohort effects.

3. In additional analyses, we did find a significant interaction between the measure of attrition and the nonlinear term for age, but only when we controlled for the interaction between race and age. Given that the significance of this interaction was relatively fragile, we chose to be conservative and not report it in our main findings, but we address this issue further in the Discussion section. 


\section{REFERENCES}

Albelda, Randy P. 1986. "Occupational Segregation by Race and Gender, 1958-1981.” Industrial and Labor Relations Review 39:404-411.

Almeida, Osvaldo P., Brian Draper, John Snowdon, Nicola T. Lautenschlager, Jane Pirkis, Gerard Byrne, Moira Sim, Nigel Stocks, Leon Flicker, and Jon J. Pfaff. 2012. "Factors Associated with Suicidal Thoughts in a Large Community Study of Older Adults." British Journal of Psychiatry 201:466-72.

Alwin, Duane. F., Scott M. Hofer, and Ryan J. McCammon. 2006. "Modeling the Effects of Time: Integrating Demographic and Developmental Perspectives." Pp. 20-38 in Handbook of the Aging and the Social Sciences, 6th ed., edited by R. H. Binstock and L. K. George. San Diego, CA: Academic Press.

Aneshensel, Carol S. 2013. Theory-based Data Analysis for the Social Sciences, 2nd ed. Thousand Oaks, CA: Sage.

Anguelov, Chris E. and Christopher R. Tamborini. 2009. "Retiring in Debt? Differences between the 1995 and 2004 Near-retiree Cohorts." Social Security Bulletin 69:13-34.

Barford Anna, Danny Dorling, George Davey Smith, and Mary Shaw. 2006. "Life Expectancy: Women Now on Top Everywhere.” BMJ 332:808.

Berthoud, Richard, Morten Blekesaune, and Ruth Hancock. 2009. "Ageing, Income and Living Standards: Evidence from the British Household Panel Survey." Ageing and Society 29:1105-22.

Bierman, Alex. 2011. "Pain and Depression in Late Life: Mastery as Mediator and Moderator." Journals of Gerontology, Series B: Psychological Sciences and Social Sciences 66:595-604.

Brown, Tyson H., Angela M. O'Rand, and Daniel E. Adkins. 2012. "Race-ethnicity and Health Trajectories: Tests of Three Hypotheses across Multiple Groups and Health Outcomes." Journal of Health and Social Behavior 53:359-77.

Cook, Fay Lomax and Richard A. Settersten. 1995. "Expenditure Patterns by Age and Income among Mature Adults: Does Age Matter?" Gerontologist 35:10-23.

Crystal, Stephen and Keith Waehrer. 1996. "Later-life Economic Inequality in Longitudinal Perspective." Journals of Gerontology 51B:S307-S318.

Dannefer, Dale. 1987. “Aging as Intracohort Differentiation: Accentuation, the Matthew Effect, and the Life Course." Sociological Forum 2:211-36.

Dannefer, Dale. 2003. "Cumulative Advantage/ Disadvantage and the Life Course: Cross-fertilizing Age and Social Science Theory." Journal of Gerontology: Social Sciences 58B:S327-S337.

Danziger, Sheldon, Jacques Van Der Gaag, Eugene Smolensky, and Michael K. Taussig. 1982. "The Life-cycle Hypothesis and the Consumption
Behavior of the Elderly." Journal of Post Keynesian Economics 5:208-27.

Denton, Margaret and Linda Boos. 2007. "Gender Gap in Wealth: Structural and Material Constraints." Journal of Women \& Aging 19:105-20.

Dupre, Matthew E. 2007. "Educational Differences in Age-related Patterns of Disease: Reconsidering the Cumulative Disadvantage and Age-as-leveler Hypotheses." Journal of Health and Social Behavior 48:1-15.

Elder, Glen H., Jr. 1987. "War Mobilization and the Life Course: A Cohort of World War II Veterans." Sociological Forum 2:449-72.

Elder, Glen H., Jr., Michael J. Shanahan, and Elizabeth Colerick Clipp. 1994. "When War Comes to Men's Lives: Life Course Patterns in Family, Work and Health." Psychology and Aging 9:5-16.

Elman, Cheryl and Angela M. O'Rand. 2004. "The Race Is to the Swift: Socioeconomic Origins, Adult Education, and Wage Attainment." American Journal of Sociology 110:123-60.

Enders, Craig. 2013. "Centering Predictors and Contextual Effects." Pp. 89-109 in The Sage Handbook of Multilevel Modeling, edited by M. Scott, J. Simonoff, and B. Marx. London, UK: Sage.

Fox, John. 2008. Applied Regression Analysis and Generalized Linear Models. Thousan Oaks, CA: Sage.

Gall, Terry Lynn and David R. Evans. 2000. "Preretirement Expectations and the Quality of Life of Male Retirees in Later Retirement." Canadian Journal of Behavioural Science 32:187-97.

Goetting, Marsha, M. Valora Raiser, Peter Martin, Leonard W. Poon, and Mary Ann Johnson. 1996. "Older Women's Financial Resources and Perception of Financial Adequacy.” Journal of Women \& Aging 7:67-81.

Gokhale, Jagadeesh, Laurence J. Kotlikoff, and John Sabelhaus. 1996. "Understanding the Postwar Decline in US Saving: A Cohort Analysis." Brookings Papers on Economic Activity 1:315-90.

Hardy, Melissa A. 2009. "Income Inequality in Later Life.” Pp. 493-518 in International Handbook of Population Aging, edited by P. Uhlenberg. New York, NY: Springer.

Hayes, Andrew F. and Li Cai. 2007. "Using Heteroscedasticity-consistent Standard Error Estimators in OLS Regression: An Introduction and Software Implementation.” Behavior Research Methods 39:709-22.

Hoffman, Lesa and Robert S. Stawski. 2009. "Persons as Contexts: Evaluating Between-person and Withinperson Effects in Longitudinal Analysis." Research in Human Development 6:97-120.

Hughes, Mary Elizabeth and Angela M. O'Rand. 2004. The American People Census 2000: The Lives and Times of the Baby Boomers. New York, NY: Russell Sage Foundation.

Jianakoplos, Nancy Ammon and Alexandra Bernasek. 2006. "Financial Risk Taking by Age and Birth Cohort." Southern Economic Journal 72:981-1001. 
Keith, Verna M. 1993. "Gender, Financial Strain, and Psychological Distress among Older Adults." Research on Aging 15:123-47.

Kim, Hyungsoo and Jinkook Lee. 2005. "Unequal Effects of Elders' Health Problems on Wealth Depletion across Race and Ethnicity." Journal of Consumer Affairs 39:148-72.

Kim, Hyungsoo, Wonah Yoon, and Karen A. Zurlo. 2012. "Health Shocks, Out-of-pocket Medical Expenses and Consumer Debt Among Middle-aged and Older Americans." Journal of Consumer Affairs 46:357-80.

Keyes, Katherine M., Rebecca L. Utz, Whitney Robinson, and Guohua Li. 2010. "What Is a Cohort Effect? Comparison of Three Statistical Methods for Modeling Cohort Effects in Obesity Prevalence in the United States, 1971-2006." Social Science and Medicine 70:1100-1108.

Krause, Neal. 1993. "Race Differences in Life Satisfaction among Aged Men and Women." Journal of Gerontology: Social Sciences 48:S235-S244.

Kwate, Naa Oyo A. 2008. "Fried Chicken and Fresh Apples: Racial Segregation as a Fundamental Cause of Fast Food Density in Black Neighborhoods." Health and Place 14:32-44.

Lee, Yoon G. 2004. "Financial Status of Older Americans Aged 70 and Above: A Comparison of Successive Age Cohorts." Hallym International Journal of Aging 6:37-55.

Lee, Jinkook and Hyungsoo Kim. 2008. “A Longitudinal Analysis of the Impact of Health Shocks on the Wealth of Elders." Journal of Population Economics 21:217-30.

Levecque, Katia, Ronan Van Rossem, Katrien De Boyser, Sarah Van de Velde, and Piet Bracke. 2011. "Economic Hardship and Depression across the Life Course: The Impact of Welfare State Regimes." Journal of Health and Social Behavior 52:262-76.

Lynch, Scott M. 2003. "Cohort and Life-course Patterns in the Relationship between Education and Health: A Hierarchical Approach.” Demography 40:309-31.

Lynch, Scott M. 2008. "Race, Socioeconomic Status, and Health in Life-course Perspective: Introduction to the Special Issue." Research on Aging 30:127-36.

McClendon, McKee J. 2002. Multiple Regression and Causal Analysis. Prospect Heights, IL: Waveland Press.

Milkie, Melissa A., Alex Bierman, and Scott Schieman. 2008. "How Adult Children Influence Older Parents' Mental Health: Integrating Stress-process and Lifecourse Perspectives.” Social Psychology Quarterly 71:86-105.

Mirowsky, John and Catherine E. Ross. 1999a. "Economic Hardship across the Life Course." American Sociological Review 64:548-69.

Mirowsky, John and Catherine E. Ross. 1999b. "Economic Hardship Declines with Age: Reply to Hardy
\& Hazelrigg." American Sociological Review 64: $577-84$

Mirowsky, John and Catherine Ross. 2010. "Well-Being across the Life Course." Pp. 361-83 in A Handbook for the Study of Mental Health, Second Edition: Social Contexts, Theories, and Systems, edited by T. L. Scheid and T. N. Brown. Cambridge, UK: Cambridge University Press.

Miyazaki, Yasuo and Stephen W. Raudenbush. 2000. "Tests for Linkage of Multiple Cohorts in an Accelerated Longitudinal Design." Psychological Methods 5:44-63.

Morland, Kimberly, Steve Wing, Ana Diez Roux, and Charles Poole. 2002. "Neighborhood Characteristics Associated with the Location of Food Stores and Food Service Places." American Journal of Preventative Medicine 22:23-29.

Offer, Avner. 2006. The Challenge of Affluence: Selfcontrol and Well-being in the United States and Britain Since 1950. Oxford, UK: Oxford University Press.

O'Rand, Angela M. 2002. "Cumulative Advantage Theory in Life Course Research." Annual Review of Gerontology and Geriatrics 22:14-20.

Pearlin, Leonard I. 1999. "The Stress Process Revisited: Reflections on Concepts and Their Interrelationships." Pp. 395-415 in Handbook of the Sociology of Mental Health, edited by C. S. Aneshensel and J. C. Phelan. New York, NY: Plenum.

Pearlin, Leonard I. and Alex Bierman. 2013. "Current Issues and Future Directions in Research into the Stress Process." Pp. 325-340 in Handbook of the Sociology of Mental Health, 2nd ed., edited by C. S. Aneshensel, J. C. Phelan, and A. Bierman. Dordrecht, Netherlands: Springer.

Pearlin, Leonard, Morton Lieberman, Elizabeth Menaghan, and Joseph T. Mullen. 1981. "The Stress Process." Journal of Health and Social Behavior 22: 337-56.

Phelan, Jo C., Bruce G. Link, and Parisa Tehranifar. 2010. "Social Conditions as Fundamental Causes of Health Inequalities Theory, Evidence, and Policy Implications." Journal of Health and Social Behavior 51: S28-S40.

Plagnol, Anke C. 2011. "Financial Satisfaction over the Life Course: The Influence of Assets and Liabilities.” Journal of Economic Psychology 32:45-64.

Pudrovska, Tetyana, Scott Schieman, Leonard I. Pearlin, and Kim Nguyen. 2005. "The Sense of Mastery as a Mediator and Moderator in the Association between Economic Hardship and Health in Late Life." Journal of Aging and Health 17:634-60.

Schieman, Scott and Gabriele Plickert. 2007. "Functional Limitations and Changes in Levels of Depression among Older Adults: A Multiple-hierarchy Stratification Perspective." Journal of Gerontology: Social Sciences 62B:S36-S42. 
Shea, Dennis G., Toni Miles, and Mark Hayward. 1996. "The Health-wealth Connection: Racial Differences." Gerontologist 36:342-49.

Short, Kathleen. 2012. "The Research Supplemental Poverty Measure: 2011." Current Population Reports. Retrieved July 17, 2103 (http://www.cen sus.gov/prod/2012pubs/p60-244.pdf).

Siminski, Peter and Oleg Yerokhin. 2012. "Is the Age Gradient in Self-reported Material Hardship Explained by Resources, Needs, Behaviours or Reporting Bias?" Review of Income and Wealth 58: 715-41.

Smith, Joan. 1987. "Transforming Households: Working-class Women and Economic Crisis.” Social Problems 34:416-36.

Snijders, Tom and Roel Bosker. 2012. Multilevel Analysis: An Introduction to Basic and Applied Multilevel Analysis, 2nd ed. London, UK: Sage.

Stoller, Michael Alan and Eleanor Palo Stoller. 2003. "Perceived Income Adequacy among Elderly Retirees." Journal of Applied Gerontology 22:230-51.

Szanton, Sarah L., Jerilyn K. Allen, Roland J. Thorpe Jr., Teresa Seeman, Karen Bandeen-Roche, and Linda P. Fried. 2008. "Effect of Financial Strain on Mortality in Community-dwelling Older Women." Journals of Gerontology: Social Sciences 63B: S369-S374.

Szanton, Sarah L., Roland J. Thorpe, and Laura N. Gitlin. 2014. "Beat the Blues Decreases Depression in Financially Strained Older AfricanAmerican Adults." American Journal of Geriatric Psychiatry 22:692-7.

Treiman, Donald J. 1992. "Status Attainment." Pp. 2090-96 in Encyclopedia of Sociology, edited by E. F. Borgatta and M. L. Borgatta. New York, NY: Macmillan.

Warren, John Robert, Jennifer T. Sheridan, and Robert M. Hauser. 2002. "Occupational Stratification across the Life Course: Evidence from the Wisconsin Longitudinal." American Sociological Review 67: 432-55.

Williams, David R. and Chiquita Collins. 2001. "Racial Residential Segregation: A Fundamental Cause of Racial Disparities in Health." Public Health Reports 116:404-16.

Williams, David R. and Michelle Sternthal. 2010. "Understanding Racial-ethnic Disparities in Health: Sociological Contributions." Journal of Health and Social Behavior 51:S15-S26.

Wolff, Edward N. 2002. "Income, Wealth, and Late-life Inequality in the United States." Annual Review of Gerontology and Geriatrics 22:31-58.

Yang, Yang and Kenneth C. Land. 2013. Age-period-cohort Analysis: New Models, Methods, and Empirical Applications. Boca Raton, FL: CRC Press.

Yang, Yang and Linda C. Lee. 2009. "Sex and Race Disparities in Health: Cohort Variations in Life Course Patterns." Social Forces 84:2093-24. 